\title{
ADD ME AS A FRIEND: APLICANDO PERSONAS COMO INSTRUMENTO GERADOR DE EMPATIA PARA APROXIMAR O DESIGNER DOS USUÁRIOS DE WAYFINDING DESIGN
}

\author{
Gabriel Gallina \\ UNISINOS \\ arq.gallina@gmail.com \\ Filipe Campelo Xavier da Costa \\ UNISINOS \\ fcampelo@unisinos.br
}

Resumo: Dentro do composto de abordagens entendido como Experiential Graphic Design, o Wayfinding Design é a disciplina que garante ao usuário seu sentido da localização e orientação dentro de um determinado ambiente. Visto que muitos projetos são adaptados conforme o tipo de público a ser contemplado, identificar quem são estes usuários é tarefa essencial durante a problematização de design, pois, para serem atendidos, os usuários precisam ser antes conhecidos. Entretanto percebe-se que, na prática, pesquisas etnográficas nem sempre acontecem. A interpretação sobre usuários fica a cargo da observação subjetiva do próprio designer, o que permite resultados que desconsideram aspectos de empatia. O Wayfinding Design necessita de instrumentos práticos voltados à compreensão de modelos mentais para, a partir de um formato mais acessível, alcançar diretrizes de projeto através da empatia. O objetivo deste artigo é apresentar um estudo de caso em que foi aplicado o instrumento Personas em um projeto real de Wayfinding. Este estudo se utilizou de redes sociais como Facebook e Pinterest para criar o elo entre Personas e o designer. Entende-se que esta é uma investigação relevante e que pode ser vista como uma contribuição metodológica inovadora para a prática de projetos desta natureza.

Palavras-chave: Wayfinding Design, Instrumentos, Personas, Rede social.

\begin{abstract}
Within the approach mix known as Experiential Graphic Design, Wayfinding Design is the discipline that assures the user his sense of location and orientation within a given environment. Since many projects are adapted according to the target public, a key task when reflecting about design is to identify who are these users, since they must be known prior to being serviced. However, practical experience shows that ethnographic research does not always takes place. The subjective observation of the designer himself is entrusted with the interpretation of users, allowing results that neglect empathy aspects. Wayfinding design needs practical tools directed at understanding mental models in order to comprehend how problems are laid out and, starting from a more accessible format, achieve project guidelines through empathy. This paper propose to present a case study which we applied Personas tool in a real wayfinding project. This study used social networks like Facebook and Pinterest to link
\end{abstract}


Personas and designers. This is a relevant research and can be seen as an innovation method for the wayfinding design practice.

Keywords: Wayfinding Design, Design Tools, Personas, Social Network.

\section{INTRODUÇÃO}

No decorrer do século XX novas especializações no campo aplicado do design surgiram em resposta à necessidade de qualificar a relação entre o homem e os ambientes. Os espaços que experienciamos - públicos, comerciais ou privados dependem do design para comunicar identidade e informação, moldando assim nossa percepção e memória sobre o local, e também animando, enriquecendo e humanizando nossas vidas (POULIN, 2012, p.11). Dentro deste composto de abordagens entendido como Experiential Graphic Design, o wayfinding é a disciplina que garante ao usuário sua navegação, sentido da localização e orientação dentro de um determinado ambiente. O papel do designer neste contexto é essencial pois "quando um ambiente tem sua comunicação visual controlada e elaborada por um designer, sua eficácia é aumentada consideravelmente" (FOLLIS;HAMMER, 1979, p.18). Se entendermos como eficácia da organização destes ambientes a otimização de seus fluxos, sua legibilidade e funcionalidade, podemos dizer que o projeto de wayfinding só fará sentido como emissor de informação quando encontra e atende seu receptor.

Talvez mais do que outras áreas do Experiential Graphic Design, se percebe relevância no wayfinding por este atender questões básicas relacionadas à qualidade de vida das pessoas, guiando e facilitando suas ações nos mais diversos ambientes. Assim, muitos projetos são adaptados conforme o tipo de público a ser atendido, correspondendo às expectativas técnicas, sociais e sensoriais por ele exigidas. Logo, identificar quem são estes usuários é tarefa essencial durante a problematização de design, pois, para serem atendidos, os usuários precisam ser antes conhecidos. A pesquisa sobre o perfil dos usuários de um determinado ambiente é relevante para compreendermos de maneira aprofundada suas pré-disposições, limitações, comportamentos e expectativas, informações estas que servirão de insumo ao projeto. Porém, na prática, pesquisas etnográficas nem sempre acontecem. Seja pelo tempo e recursos que demandam, pelo pouco prazo imposto pelo cliente, ou por este entender que tal investigação não se justifica em um projeto desta natureza, o fato é que este levantamento por vezes acaba negligenciado, e a interpretação sobre usuários fica a cargo da observação do próprio designer. Isso significa que este projeta considerando seu processo intuitivo, ou seja, seu repertório mental é o influenciador das decisões. Quando um profissional direciona suas decisões de projeto no sentido de satisfazer suas percepções como usuário, está de certa forma assumindo que os gatilhos de experiência para uns - ele próprio - são os mesmos para outros - os usuários. O risco desta abordagem subjetiva é a falta de empatia, pois o esforço do designer se concentrará em questões que atendam a si próprio, quando deveria focar em quem irá, de fato, utilizar este ambiente. $O$ experiente designer Ronald Shakespear, um dos ícones do wayfinding design argentino, ressalta a importância desta relação ao dizer que "eu não trabalho para os meus clientes, eu trabalho para os clientes dos meus clientes: para as pessoas" (SHAKESPEAR, 2013). Neste sentido entende-se necessário aproximar designer e usuário de maneira simples e prática, sistematizando 
informações e potencializando seu uso no processo projetual. O wayfinding design necessita, portanto, de instrumentos práticos voltados à compreensão de modelos mentais para entender a configuração dos problemas e, a partir de um formato mais amigável, alcançar diretrizes de projeto. $O$ instrumento que sugerimos ser contributivo e pertinente para isso é Personas.

Uma Persona é uma síntese construída depois de observação exaustiva dos atuais ou potenciais usuários. Este instrumento criado por Allan Cooper na década 80 auxilia no projetar, pois tem em vista atender uma ou poucas pessoas, ao invés de tentar satisfazer inúmeras. Cada Persona é baseada em um personagem fictício cujo perfil reúne as características de um grupo social existente. Assim, as Personas assumem atributos dos grupos que representam a partir de suas características sociais e demográficas, suas necessidades, desejos, hábitos e origens culturais. 0 aspecto especial de uma descrição de Persona é justamente o destaque nas atitudes relevantes ao projeto.

Sobre o processo de organização deste instrumento, Kumar (2013, p.211) aponta a natureza dos dados que são relevantes para sua construção, bem como o que é resultante de sua elaboração. Na construção de Personas temos como input: achados de pesquisas etnográficas; lista de potenciais usuários; e lista de atributos destes usuários. Como resultados da construção de Personas temos como output: conjunto de Personas baseado em atributos dos usuários, sugerindo conceitos a explorar; e apoio ao processo de compreensão do problema sob o ponto de vista dos usuários. Sobre as vantagens do uso de Personas, Kumar identifica que este instrumento contribui estruturando o conhecimento existente a respeito dos usuários, ampliando o mindset, apontando direções criativas, facilitando o storytelling, inspirando idéias e, finalmente, construindo empatia.

Como forma de experimentação o instrumento Personas foi aplicado em um processo de projeto real de wayfinding para um empreendimento comercial. Foi feito um workshop em uma empresa de design para identificação dos usuários e criação de Personas, que seriam posteriormente representadas através de perfis pessoais fictícios em redes sociais online. Esta maneira de tangibilizar as Personas foi uma opção proposta com o intuito de promover uma aproximação com a realidade atual das relações sociais, onde o ambiente virtual assume cada vez mais protagonismo. Facebook e Pinterest são duas das principais redes sociais mundiais da atualidade, com números que ultrapassam 1 bilhão de usuários. A familiaridade dos projetistas com ambas as plataformas foi providencial no sentido de facilitar o processo de uso das Personas, assim como a aderência ao experimento. Durante semanas a equipe criativa consultou os perfis virtuais destas Personas para orientar o desenvolvimento do projeto, e os resultados desta experiência de empatia foram avaliados posteriormente em uma entrevista em grupo. Os objetivos da avaliação foram: verificar se foi útil a introdução de Personas neste contexto do wayfinding; se o uso de Personas trouxe empatia à equipe de projeto, quanto sua consciência e preocupação sobre o usuário; e como viram o uso de rede social como canal de acesso a estas Personas. Entende-se que esta é uma investigação relevante e que pode trazer implicações positivas para a prática de projetos desta natureza. 


\section{MÉTODO}

Este estudo utilizou um delineamento experimental e buscou obter informações sobre como a avaliação do perfil do usuário pode trazer insumos ao processo de um projeto específico de wayfinding design. O procedimento foi estruturado em seis etapas (Quadro 1).

Quadro 1 - Organização da pesquisa

\begin{tabular}{|c|c|c|c|}
\hline & Etapa & Atividade & Questão-chave \\
\hline 1 & $\begin{array}{l}\text { Conhecimento da prática } \\
\text { atual }\end{array}$ & $\begin{array}{l}\text { Entrevistar em } \\
\text { profundidade especialistas }\end{array}$ & Como você trabalha hoje? \\
\hline 2 & $\begin{array}{l}\text { Identificação de lacunas do } \\
\text { processo projetual e como } \\
\text { abordá-las }\end{array}$ & $\begin{array}{l}\text { Analisar as entrevistas em } \\
\text { profundidade }\end{array}$ & $\begin{array}{l}\text { Que instrumento é adequado } \\
\text { para trabalhar empatia entre } \\
\text { designer e usuário? }\end{array}$ \\
\hline 3 & $\begin{array}{l}\text { Workshop com equipe de } \\
\text { projeto }\end{array}$ & $\begin{array}{l}\text { Identificar os usuários e } \\
\text { criar Personas }\end{array}$ & $\begin{array}{l}\text { Quem é o usuário e como } \\
\text { criar esta Persona? }\end{array}$ \\
\hline 4 & $\begin{array}{l}\text { Processo projetual com o uso } \\
\text { de Personas }\end{array}$ & $\begin{array}{l}\text { Desenvolver projeto usando } \\
\text { Personas em redes sociais }\end{array}$ & $\begin{array}{l}\text { Como é acessar Personas } \\
\text { através de redes sociais }\end{array}$ \\
\hline 5 & $\begin{array}{l}\text { Análise sobre a experiência de } \\
\text { usar Personas através de } \\
\text { perfis de redes sociais }\end{array}$ & $\begin{array}{l}\text { Entrevistar em } \\
\text { profundidade projetistas }\end{array}$ & $\begin{array}{l}\text { Como foi o uso deste } \\
\text { instrumento de design? }\end{array}$ \\
\hline 6 & Avaliação dos resultados & Compreender o processo & $\begin{array}{l}\text { Como se dá esta relação } \\
\text { Persona/rede social/projeto? }\end{array}$ \\
\hline
\end{tabular}

Fonte: Elaborado pelo autor, com base na pesquisa realizada.

O grupo de respondentes foi constituído por 6 especialistas de 6 diferentes empresas brasileiras de design, onde estes atuam profissionalmente dedicados à elaboração de projetos de wayfinding (Quadro 2).

Quadro 2 - Caracterização dos especialistas entrevistados

\begin{tabular}{|l|c|c|l|l|l|}
\hline & Sexo & Idade & \multicolumn{1}{|c|}{ Titulação } & $\begin{array}{c}\text { Tempo de } \\
\text { experiência }\end{array}$ & \multicolumn{1}{|c|}{ Representação } \\
\hline Especialista 1 & $\mathrm{M}$ & 34 & Designer / Mestre & 8 anos & Coordenador de projetos \\
\hline Especialista 2 & $\mathrm{M}$ & 28 & Arquiteto e Designer & 6 anos & Coordenador de projetos \\
\hline Especialista 3 & $\mathrm{M}$ & 37 & Arquiteto/Especialista & 3 anos & Coordenador de projetos \\
\hline Especialista 4 & $\mathrm{F}$ & 29 & Designer/Mestranda & 6 anos & Assistente de projetos \\
\hline Especialista 5 & $\mathrm{F}$ & 34 & Arquiteta/Especialista & 10 anos & Diretora de empresa \\
\hline Especialista 6 & $\mathrm{M}$ & 39 & Publicitário/Mestre & 15 anos & Diretor de empresa \\
\hline
\end{tabular}

Fonte: Elaborado pelo autor, com base na pesquisa realizada.

Para o levantamento inicial discutiu-se sobre seus entendimentos e processos empregados no conhecimento e trato das informações sobre o usuário. Para isso foram feitas entrevistas em profundidade dentro do intervalo de duas semanas, e em seguida iniciou-se o processo de transcrição das mesmas. As entrevistas com os especialistas tiveram como objetivo compreender, dentro de um contexto existente e baseado na prática do dia-a-dia, se seus processos projetuais obedeciam uma metodologia centrada no usuário ou se estavam baseados no conhecimento provindo da vivência profissional. Na análise se identificou a ausência de padrão referente ao 
trato ou uso de instrumentos que auxiliassem na geração de empatia do designer para com os usuários. Diante disso verificou-se como os especialistas compreendem e utilizam a experiência do usuário em seus projetos, onde constatamos ser uma prática incomum ou desestruturada. Os tópicos gerais abordados nestas entrevistas foram: percepção sobre seu processo analítico criativo; percepção sobre o uso de pesquisa formal a respeito do usuário; reflexão sobre a importância do conhecimento a respeito do usuário para o desenvolvimento de projetos de wayfinding; como se dá o uso dos dados e de que maneira o projetista se apropria deles. Compreendida a lacuna entre o designer e o usuário final, no que diz respeito aos aspectos de empatia, a pesquisa seguiu para a fase seguinte em que foi proposto um experimento utilizando o instrumento Personas.

Nesta fase da pesquisa foi feito um workshop na sede de uma empresa de design, de porte médio ( 9 pessoas) e atuante no mercado nacional e internacional há 7 anos. Este workshop contou com um facilitador (pesquisador) e 4 participantes (projetistas). O objeto que contextualiza este estudo é um projeto real de wayfinding design para um empreendimento comercial elaborado por uma grande incorporadora brasileira. O empreendimento apresenta uma torre única de 13 pavimentos, contém 190 salas comerciais, hall de acesso e áreas comuns no pavimento térreo, e um estacionamento subterrâneo, somando aproximadamente $2.140 \mathrm{~m}^{2}$ de área total. No momento do workshop este projeto se encontrava na fase de levantamento de dados. A diretora da empresa de design apresentou ao grupo o material comercial e concept design do empreendimento, como forma de dar um panorama geral a respeito do projeto arquitetônico. Foi recebido da incorporadora uma pré-definição comercial do público-alvo, representado basicamente por pequenas empresas e profissionais liberais autônomos que necessitam de pouca estrutura ou espaço físico para realizar suas atividades. Através deste perfil de público, ao qual a comercialização das unidades estava sendo amplamente dirigida, a equipe do workshop começou a traçar quem seriam os clientes destes profissionais, ou seja, quem iria transitar pelo empreendimento e mais necessitaria do sistema de wayfinding para se orientar.

Para cada grupo foram listadas características preliminares de usuários que, pelo perfil apontado inicialmente pela incorporadora, possivelmente seria o público circulante (Quadro 3).

Quadro 3 - Relação de usuários

\begin{tabular}{|l|l|l|}
\hline \multicolumn{1}{|c|}{ Grupo } & \multicolumn{1}{|c|}{ O que faz } & \multicolumn{1}{c|}{ Usuário } \\
\hline \multirow{2}{*}{ PROFISSIONAL } & $\begin{array}{l}\text { Usuário que habita a sala comercial e } \\
\text { presta diariamente seus serviços } \\
\text { neste edifício }\end{array}$ & 1. Nutricionista \\
\cline { 3 - 3 } CLIENTE & $\begin{array}{l}\text { Usuário que visita periodicamente a } \\
\text { sala do profissional deste edifício }\end{array}$ & 2. Advogado \\
\cline { 2 - 3 } & 4. Cliente de nutricionista \\
\hline MANUTENÇÃO E APOIO & $\begin{array}{l}\text { Usuário que dá suporte de serviços e } \\
\text { faz a manutenção deste edifício }\end{array}$ & 5. Serviços / Terceirizado \\
\hline
\end{tabular}

Fonte: Elaborado pelo autor, com base na pesquisa realizada.

A partir do Quadro 3 iniciou-se um processo conjunto de construção de cada Persona, onde a equipe partiu para definições que caracterizassem e tangibilizassem o 
perfil destes usuários que circulariam no edifício e fariam uso do sistema de wayfinding (Quadro 4). A equipe atribuiu para cada Persona um nome, idade, profissão, características pessoais e comportamentais, e aspectos relacionados ao uso que esta Persona faz das dependências do edifício, bem como sua rotina e trajetos internos, considerando chegadas e saídas.

\section{Quadro 4 - Definição das Personas}

\begin{tabular}{|c|c|c|}
\hline Grupo & O que faz & Persona \\
\hline \multirow{2}{*}{ PROFISSIONAL } & \multirow{2}{*}{$\begin{array}{l}\text { Usuário que } \\
\text { habita a sala } \\
\text { comercial e } \\
\text { presta } \\
\text { diariamente } \\
\text { seus serviços } \\
\text { neste edifício }\end{array}$} & $\begin{array}{l}\text { Ingrid Muller / Mulher, } 35 \text { anos, nutricionista. } \\
\text { Ingrid é casada, bem de vida, tem horário flexível, divide a sala } \\
\text { com uma outra nutricionista, é magra e alta, anda de salto alto, } \\
\text { chega de carro pela garagem e vai direto para a sala dela } \\
\text { usando o elevador, não utiliza as áreas comuns. }\end{array}$ \\
\hline & & $\begin{array}{l}\text { Jorge Medeiros / Homem, } 50 \text { anos, advogado. } \\
\text { Jorge é casado há } 25 \text { anos, tem } 3 \text { filhos, um dos filhos trabalha } \\
\text { com ele, cumpre uma rotina de trabalho, vem de carro, mas } \\
\text { usa bastante os serviços da rua, almoça na rua, usa com } \\
\text { frequência a sala de reuniões da área comum. }\end{array}$ \\
\hline \multirow{2}{*}{ CLIENTE } & \multirow{2}{*}{$\begin{array}{l}\text { Usuário que } \\
\text { visita } \\
\text { periodicamente } \\
\text { a sala do } \\
\text { profissional } \\
\text { deste edifício }\end{array}$} & $\begin{array}{l}\text { Clara Santos / Mulher, } 20 \text { anos, gestante, estudante. } \\
\text { Clara é cliente de Ingrid, mora com os pais, é meio desligada, é } \\
\text { flexível e leve, tem mais tempo, usa as lojas externas do } \\
\text { edifício, caminha olhando o celular, chega a pé e entra pela } \\
\text { recepção. }\end{array}$ \\
\hline & & $\begin{array}{l}\text { Rafael Casteli / Homem, } 45 \text { anos, empresário. } \\
\text { Rafael é cliente de Jorge, classe-média, está resolvendo um } \\
\text { inventário, chega de carro e usa o estacionamento rotativo do } \\
\text { edifício, não tem muito tempo a perder, é bem agilizado, lidera } \\
\text { a família, anda de calça e camisa para dentro. }\end{array}$ \\
\hline MANUTENÇÃO & $\begin{array}{l}\text { Usuário que dá } \\
\text { suporte de } \\
\text { serviços e faz a } \\
\text { manutenção } \\
\text { deste edifício }\end{array}$ & $\begin{array}{l}\text { Paulo Oliveira / Homem, } 25 \text { anos, 20 grau e curso técnico, } \\
\text { eletricista terceirizado. } \\
\text { Paulo tem um filho pequeno, é bem agilizado e gosta de } \\
\text { resolver rapidamente as coisas, é gremista e frequenta o } \\
\text { estádio, o toque de seu celular é o hino de seu time, usa } \\
\text { camiseta cinza e kit de ferramentas, chega pela recepção, usa } \\
\text { os elevadores, precisa de acesso às áreas técnicas do edifício, } \\
\text { chega de camionete e a deixa na rua. }\end{array}$ \\
\hline
\end{tabular}

Fonte: Elaborado pelo autor, com base na pesquisa realizada.

Finalizada esta etapa do workshop, foi definido pelo grupo que os integrantes se dividiriam na criação do perfil fictício das Personas elaboradas nas redes sociais online. As informações pensadas e discutidas na construção de cada Persona seriam então inseridas e ampliadas por escrito em cada perfil de Facebook, bem como seu universo visual explorado através de painéis no Pinterest.

Dado o período de 30 dias para experimentação do instrumento no contexto do projeto, reuniram-se novamente os projetistas para uma entrevista tipo grupo focal, quando foram basicamente apresentados e discutidos os resultados desta experiência. A entrevista final ocorreu em grupo com os mesmos integrantes do workshop, foi gravada e seguiu um roteiro semiestruturado, momento em que as questões foram colocadas pelo pesquisador de forma a estimular respostas descritivas. Os tópicos abordados nesta entrevista foram: Percepção ao utilizar o instrumento Personas; Pertinência deste instrumento para um projeto de wayfinding; Reflexão sobre a 
contribuição deste instrumento no contexto projetual; Descrição operacional de como e com que frequência recorreu às Personas; Percepção do uso de redes sociais como canal de acesso a estas Personas; Reflexão sobre o resultado final percebido pelo cliente. A análise de conteúdo (MORAES, 1999) desta entrevista foi feita objetivando compreender se Personas contribui como instrumento de design, conforme vantagens levantadas por Kumar (2013, p.211).

Como forma de tangibilizar estas Personas foi elaborado, para cada uma, um perfil de Pinterest (Figura 1), seu painel correspondente (Figura 2) e perfil pessoal de Facebook (Figura 3). Conforme já mencionado, esta construção teve como intuito tangibilizar os usuários deste empreendimento e então facilitar a criação de empatia por parte dos projetistas para com o usuário final, visto que este agora aparentemente existia virtualmente.

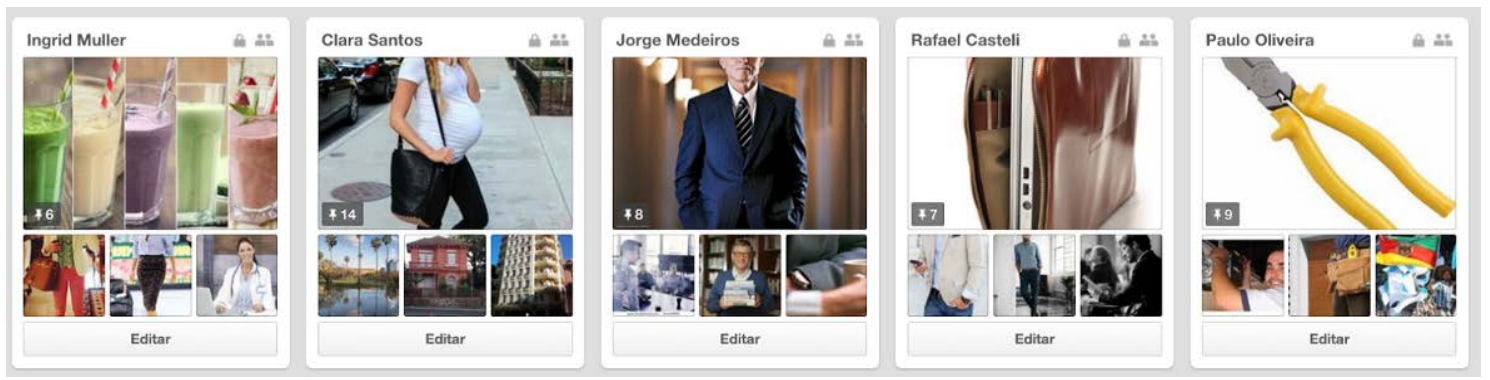

Figura 1 - Perfil das cinco Personas no Pinterest

Fonte: Elaborado pelo autor, com base na pesquisa realizada.

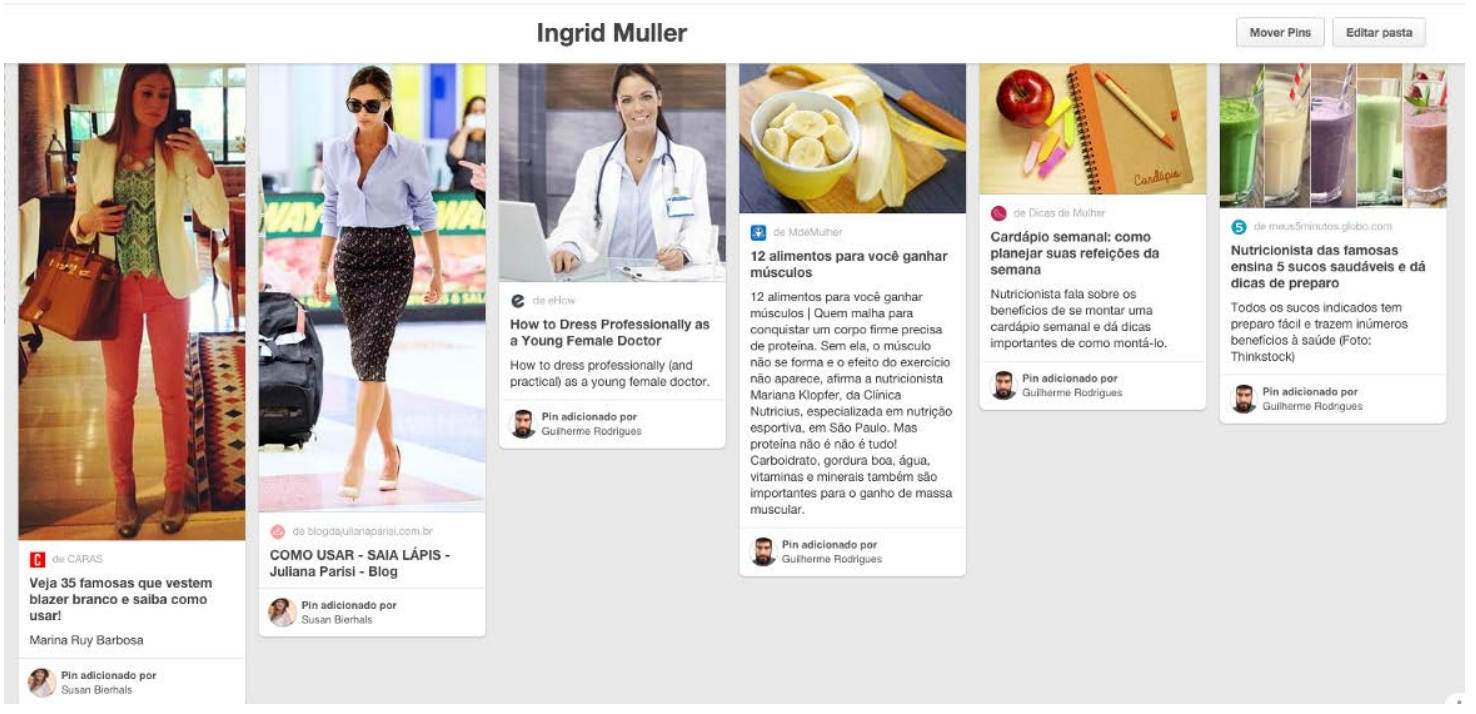

Figura 2 - Painel da Persona Ingrid Muller no Pinterest

Fonte: Elaborado pelo autor, com base na pesquisa realizada.

$\mathrm{Na}$ percepção do grupo o Facebook, por apresentar um processo mais burocrático no cadastro e gerenciamento de informações iniciais, exigiu mais esforço para construção dos perfis. Existir um perfil acessível das Personas nesta rede social trouxe a impressão de que as pessoas existiam realmente, embora o fato de que seus perfis não tivessem movimentação ou interação (os perfis não eram atualizados constantemente) enfraquecia um pouco sua presença ou lembrança no contexto de 
projeto. Percebeu-se que, no uso da ferramenta Facebook, se gastaria uma energia considerável no gerenciamento e atualização destes perfis, tempo este que deveria ser melhor utilizado pensando o projeto propriamente dito. O grupo entendeu que o Facebook é uma rede social para externar comportamentos, como por exemplo 'quero que as pessoas vejam quem eu sou, o que fiz, onde fui e com quem eu estava'. 0 Pinterest é o inverso, é uma rede social mais intimista e pessoal, onde o usuário realiza algo como 'vi isso e quero guardar para depois, quando precisar'. Na prática, o Pinterest foi a rede social mais utilizada pelo grupo em razão da combinação entre bom apelo visual e praticidade de manuseio. Para projetos de wayfinding o Pinterest parece ser mais eficaz como ferramenta, pois mostra o que é mais relevante para aquela Persona e auxilia na construção de um repertório visual comportamental bastante útil ao designer.
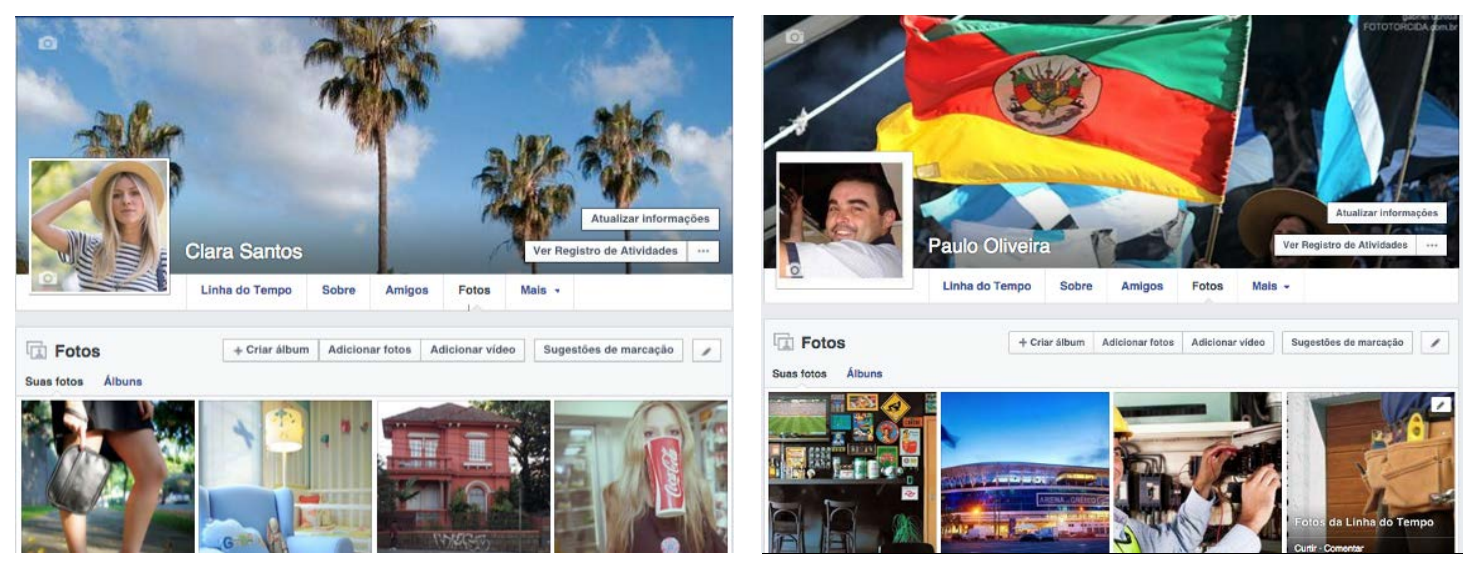

Figura 3 - Perfil das Personas Clara e Paulo no Facebook

Fonte: Elaborado pelo autor, com base na pesquisa realizada.

Em termos gerais, a equipe sentiu-se satisfeita com o exercício do processo de criação de Personas. Entretanto identificou a criação de perfis no Facebook como quase desnecessária diante da dificuldade proporcionada pelo número de etapas cadastrais do sistema e da necessidade de atualização constante - fato que não houve no experimento. O ponto é que, da maneira como foi utilizado, o Facebook não se mostrou aos olhos dos projetistas ser uma ferramenta prática e adequada.

No que se refere ao uso de Personas como instrumento, o grupo entendeu ser uma forma bastante efetiva de aproximação com o usuário e suas necessidades reais. Sendo profissionais projetistas habituados a demandas semelhantes, estes tinham a percepção de que o público-alvo de um projeto de wayfinding design consistia em um agrupamento genérico de perfis diversificados, logo perceberam que nunca haviam chegado tão próximos ao ponto de conhecê-los e entender suas necessidades. Além dos aspectos ligados à empatia, o uso deste instrumento acabou auxiliando tanto na etapa de lançamento preliminar de ideias como na de avaliação dos resultados, em que ocorreu a validação dos caminhos conceituais escolhidos diante do seu atendimento ou não às necessidades daquelas Personas previamente definidas. Ter as Personas presentes no contexto do processo de projeto trouxe uma percepção de segurança e confiança aos designers, pois os mesmos se sentiam amparados pelo fato do desenvolvimento do trabalho estar sendo dirigido a um usuário quase real, 
vantagem propiciada por estarem materializados em redes sociais. O projeto seguiu um caminho bastante coeso e correto, aos olhos dos designers, pois notadamente atendia àqueles usuários representados pelas Personas. Percebeu-se, entretanto, uma certa angústia com este instrumento no que diz respeito ao fato de que, no momento de criação das Personas, o processo trazer à tona a rotulação de pessoas. Foi visto que a tendência a estereotipar ou lidar com extremos vem a facilitar a criação da Persona, embora o grupo tenha compreendido que esta não seja a prática mais correta para construção dos perfis pelo risco de adentrar discussões de preconceito.

Com relação à aplicação deste instrumento para um tipo de projeto específico (wayfinding design) os designers encontraram Personas como um recurso de bastante utilidade, visto que imaginavam o percurso individual de cada usuário nos ambientes do empreendimento (por onde ela chega, aonde ela vai, por onde ela sai, etc), proporcionando um olhar mais apurado no atendimento de suas necessidades de identificação, direcionamento e informação a respeito dos ambientes externos e internos. Através de Personas o projetista parece mudar o foco técnico e racional para uma perspectiva mais lúdica, em que visualiza de maneira mais clara o mapa da jornada daquela pessoa. O projeto ganhou em objetividade, pois o instrumento apontou caminhos e critérios a serem seguidos, direcionando tanto para onde ir como para onde não ir. O grupo comentou que, diferentemente de outros projetos da mesma natureza quando na pesquisa de referências eram reunidas inúmeras imagens sem critérios claros, agora com a presença das Personas este tipo de pesquisa já foi mais dirigida e restrita, focando no atendimento daquele usuário e não nas predileções estéticas do designer.

Foi interessante verificar como este instrumento foi útil na elaboração de diretrizes projetuais do sistema de wayfinding. Como forma de construção destes parâmetros, a equipe elaborou por conta própria um gráfico de relação entre Personas e uma série de atributos percebidos de um projeto de wayfinding. De acordo com o perfil de cada Persona, os projetistas pontuaram que atributos Ihes seriam mais significativos (Figura 4) através de consultas aos perfis no Pinterest e Facebook.

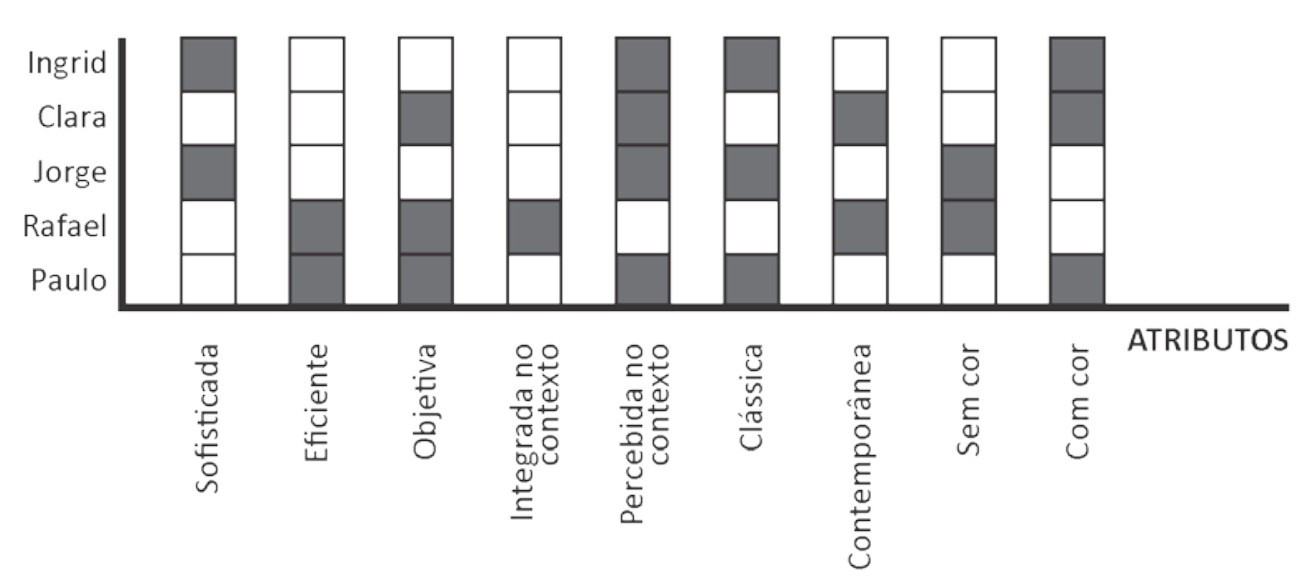

Figura 4 - Como as Personas percebem a sinalização/wayfinding do empreendimento

Fonte: Adaptado pelo autor a partir da apresentação elaborada pela empresa de design ao cliente 
Após este exercício, os atributos que tiveram mais peso sob a ótica das Personas (Figura 5) acabaram sendo definidos como diretrizes projetuais (Figura 6), mostrando que, de fato, este instrumento foi útil para a tomada de decisão do caminho criativo a ser explorado nos estudos preliminares.

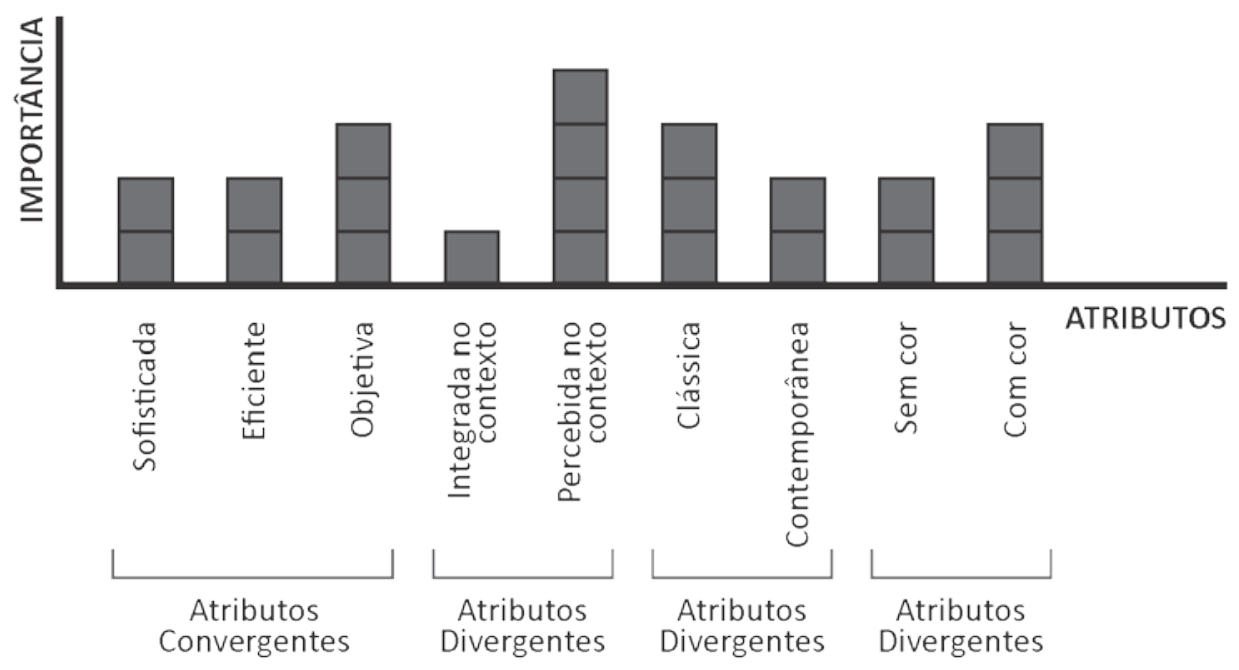

Figura 5 - Compilação dos resultados: relevância de atributos

Fonte: Adaptado pelo autor a partir da apresentação elaborada pela empresa de design ao cliente

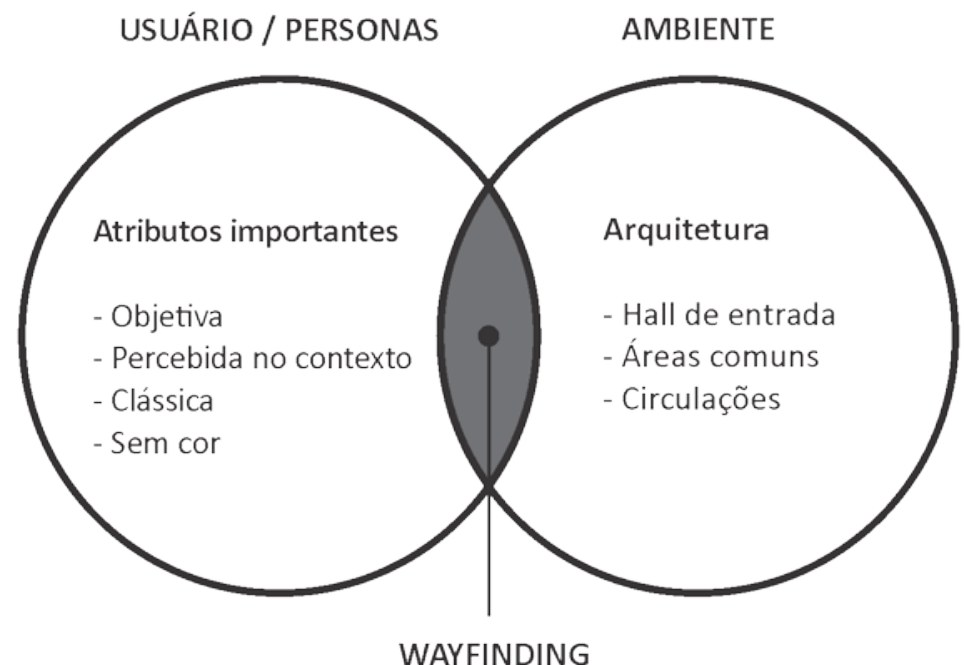

Figura 6 - Premissas de projeto

Fonte: Adaptado pelo autor a partir da apresentação elaborada pela empresa de design ao cliente

É importante relatar o momento pós-experimento quando, finalizado o estudo preliminar do projeto de wayfinding design e apresentado os resultados ao cliente, se anunciou que o mesmo fez uso do instrumento Personas. Os projetistas perceberam que o cliente ficou mais interessado pelo projeto diante do entendimento de que houve um processo analítico-criativo mais aprofundado e discutido, que densificava a solução apresentada. Aos olhos do cliente o uso deste instrumento qualificou ainda mais o projeto, pois tangibilizou aspectos de empatia que, comprovadamente, foram 
considerados. Neste momento é interessante trazer uma passagem de Designing for Growth, publicação em que os autores refletem a respeito da necessária aproximação dos gestores com os instrumentos de design.

O design começa com empatia, estabelecendo uma profunda compreensão sobre aqueles para quem estamos projetando. Gestores que pensam como designers devem se colocar no lugar dos seus clientes. Claro, todos nós já sabemos que devemos ser "centrados no cliente", mas o que estamos falando aqui é mais profundo e pessoal do que isso. Isso significa "conhecer" os clientes como pessoas reais, com problemas reais, e não vê-los como alvos para vendas ou como um conjunto de estatísticas demográficas como idade, nível de renda, ou estado civil. Trata-se de desenvolver um entendimento tanto emocional quanto racional de suas necessidades e desejos. (LIEDTKA; OGILVIE, 2011, p.6) ${ }^{1}$

Percebeu-se então que, tanto aos olhos do designer quanto do cliente, o uso do instrumento Personas trouxe não somente resultados criativos positivos, mas também reflexões a respeito da necessária empatia enquanto parte do processo projetual, objetivo principal deste experimento.

\section{CONSIDERAÇÕES FINAIS}

O experimento relatado neste artigo aponta que a inserção do instrumento Personas representou um importante elo entre projetista e usuário de um sistema de wayfinding. Conforme descrito, a distância entre estes dois mundos é característica deste tipo de demanda projetual, em que as necessidades relativas à identificação, informação e orientação espacial do usuário são atendidas à luz do que o designer entende ser o mais adequado, bastando, muitas vezes, de seu entendimento para tanto.

Neste contexto de desenvolvimento de um projeto de wayfinding, o uso deste instrumento foi um importante ponto de partida para o entendimento a respeito do usuário final e de suas expectativas experienciais. Imaginar o mapa da jornada de cada Persona e sua interação com os ambientes do empreendimento proporcionaram reflexões importantes. Estas reflexões acabaram resultando em diretrizes projetuais que trouxeram objetividade ao processo criativo. O uso de redes sociais como canal de acesso a estas Personas apresentou-se como um composto inovador quanto à representação deste instrumento. $O$ fato de estarem retratadas através de plataformas interativas, e não em formatos estáticos, reforçou seu realismo e garantiu um aspecto memorável e sintonizado com a atualidade. Cabe concluir que a aplicação deste instrumento atendeu ao que Kumar (2013) aponta como suas principais vantagens, pois: (a) através da criação de Personas e sua formatação em redes sociais estruturou o conhecimento sobre os usuários; (b) ampliou a percepção acerca das necessidades de wayfinding daquele empreendimento específico; (c) através de discussões sobre trajetos e percursos individuais de cada Persona, facilitou o storytelling a respeito das experiências possíveis daqueles indivíduos enquanto

\footnotetext{
${ }^{1}$ Tradução nossa a partir do texto original dos autores.
} 
inseridos naquele ambiente; (d) formalizou diretrizes de projeto a partir da análise do cruzamento destas Personas com suas percepções sobre atributos desejáveis para o design de wayfinding; (e) inspirou ideias e caminhos criativos a partir do emprego destas diretrizes e sua associação com as Personas; e (f), favoreceu o envolvimento pessoal do projetista, posicionando sua empatia para um patamar perceptivelmente elevado.

Independentemente do resultado aqui alcançado entendemos que o método aplicado é passível de aperfeiçoamentos. Verificou-se que o experimento foi bemsucedido e bem aceito em razão do uso de redes sociais como meio, proporcionando aceitação e interesse diante das Personas. Sinais de engajamento e, principalmente, empatia foram percebidos como decorrentes do uso das redes sociais. Entretanto, sugere-se para estudos práticos futuros que, no manuseio de perfis na rede social Facebook, se considere na equipe o apoio de um integrante independente, gerador de conteúdo específico para este canal. Assim, além de tornar as Personas ainda mais reais e dinâmicas através da interatividade, poupa o projetista da tarefa de gerenciar diversos perfis.

\section{REFERÊNCIAS}

FOLLIS, John; HAMMER, Dave. Architectural signing and graphics. New York: Whitney Library of Design, 1979.

HUNT, Wayne. Environmental Graphics: Projects and Process. New York, Harper Design Publisher, 2003.

KUMAR, Vijay. 101 Design methods: A structured approach for driving innovation in your organization. New Jersey, US: Ed Wiley, 2013.

MORAES, Roque. Análise de conteúdo. Revista Educação, Porto Alegre, v.22, n.37, 1999.

LIEDTKA, Jeanne; OGILVIE, Tim. Designing for Growth: A design thinking tool kit for managers. (Cap 01). New York, US: Columbia University Press, 2011.

POULIN, Richard. Graphic Design in the Built Environment: A 20th Century History. Minneapolis: Rockport, 2012.

SHAKESPEAR, Ronald. Reconocimiento Maestro del Diseño (Discurso de agradecimento). Universidad de Palermo. Buenos Aires, Argentina. 20 de agosto de 2013. Disponível na internet em: https://www.youtube.com/watch?v=c289mJnkFYQ Acesso em 02 de Fevereiro de 2016. 